\title{
A PRESENTATION ON STATICALLY INDETERMINATE
}

\section{STRUCTURES}

By

Mala Babagana Gutti

B.Eng. Student, Department of Civil and Water Resources Engineering,

University of Maiduguri, Maiduguri, Nigeria

Email: malabgutti@gmail.com

January, 2017 


\section{CONTENTS}

- Introduction.

- Structure.

- Analysis.

- Stable and Unstable Structures.

- Support Types/Components.

- Statically Determinate Structures.

- External Determinacy.

- Internal Determinacy.

- Determinacy of Beams.

- Statically Indeterminate Structures.

- Externally Indeterminacy.

- Internally Indeterminacy.

- Difference Between Determinate and Indeterminate Structures.

- Methods of Analyzing Indeterminate Structures.

- Problems and Their Solutions Involving Indeterminate Structures.

- References. 


\section{Introduction}

Before beginning to analyze a structure, it is important to know what kind of structure it is. Different types of structures may need to be analyzed using different methods. For example, structures that are determinate may be completely analyzed using only static equilibrium, whereas indeterminate structures require the use of both static equilibrium and compatibility relationships to find the internal forces. In addition, real structures must be stable. This means that the structure can recover static equilibrium after a disturbance. There is no point analyzing a structure that is not stable.

Any structure is designed for the stress resultants of bending moment, shear force, deflection, torsional stresses, and axial stresses. If these moments, shears and stresses are evaluated at various critical sections, then based on these, the proportioning can be done. Evaluation of these stresses, moments and forces and plotting them for that structural component is known as analysis. Determination of dimensions for these components of these stresses and proportioning is known as design.

\section{What is a structure?}

Structure is an assemblage of a number of components like slabs, beams, columns, walls, foundations and so on, which remains in equilibrium. It has to satisfy the fundamental criteria of strength, stiffness, economy, durability and compatibility, for its existence. It is generally classified

into two categories as Determinate structures and Indeterminate structures or Redundant structures. 


\section{Analysis}

Determinate structures are analyzed just by the use of basic equilibrium equations. By this analysis, the unknown reactions are found for the further determination of stresses. Redundant or indeterminate structures are not capable of being analyzed by mere use of basic equilibrium equations. Along with the basic equilibrium equations, some extra conditions are required to be used like compatibility conditions of deformations etc. to get the unknown reactions for drawing bending moment and shear force diagrams.

\section{Stable and Unstable Structures}

A stable structure is one that will not collapse when disturbed. Stability may also be defined as "The power to recover equilibrium ". In general, there are many ways that a structure may become unstable, including buckling of compression members, yielding/rupture of members, or nonlinear geometric effects like P-Delta; however, for linear structural analysis, the main concern is instability caused by insufficient reaction points or poor layout of structural members. An internally stable structure is one that would maintain its shape if all the reactions supports were removed. A structure that is internally unstable may still be stable if it has sufficient external support reactions.

An unstable structure generally cannot be analyzed. Therefore, it is useful to know if a structure is stable or unstable before a structural analysis is conducted. There are four main ways that a structure may be geometrically unstable. These apply only to linear geometric stability and not to instability caused by buckling, member yielding or nonlinear geometry. 


\section{Support Types/Components}

In the equations above, $r$ is equal to the total number of reaction components as follows:

1. $\operatorname{Roller}(r)=1$

2. $\operatorname{Pin}(r)=2$

3. Fixed $(r)=3$

For multiple reaction points, $(r)$ is the sum of all the components for all the reaction points in the structure.

\section{Statically Determinate Structure}

When the equations of equilibrium are sufficient to determine the forces and stresses in a structure, we say that this Structure is statically determinate.

\section{External Determinacy}

The ability to calculate all of the external reaction component forces using only static equilibrium. A structure that satisfies this requirement is externally statically determinate. A structure for which the external reactions component forces cannot be calculated using only equilibrium is externally statically indeterminate.

If a structure is externally determinate, then all of the reactions may be calculated using equilibrium alone. To calculate external determinacy, the following equations are used:

- Statically unstable externally

$$
r=3+e c
$$

- Statically determinate externally 
$r>3+e c$

- Statically indeterminate externally

where $r$ is the number of reaction components, and $e c$ is the number of equations of condition. Both of these are described in detail below.

- The degree of indeterminacy is given by the following equation:

$$
r-(3+e c)
$$

\section{Internal Determinacy}

The ability to calculate all of the external reaction component forces and internal forces using only static equilibrium. A structure that satisfies this requirement is internally statically determinate. A structure for which the internal forces cannot be calculated using only equilibrium is internally statically indeterminate.

If a structure is internally determinate, then all of the reactions and internal forces may be calculated using equilibrium alone. Internal determinacy is generally much more important than external determinacy in structural analysis. To calculate internal determinacy, the following equations are used:

- Statically unstable

$$
3 m+r<3 j+e c
$$

- Statically determinate

$$
3 m+r=3 j+e c
$$

- Statically indeterminate 


\section{$3 m+r>3 j+e c$}

where $m$ is the total number of members in the structure, $r$ is the number of reaction components, $j$ is the total number of joints in the structure, and $e c$ is the number of equations of condition. The meaning of $r$ and $e c$ are the same as for External determinacy above. The definition of members and joints will be discussed below.

The degree of indeterminacy is given by the following equation:

\section{$3 m+r-(3 j+e c)$}

\section{Determinacy of Beams}

For a coplanar (two-dimensional) beam, there are at most three equilibrium equations for each part, so that if there is a total of $n$ parts and $r$ reactions, we have;

$r=3 n$, statically determinate.

$r>3 n$, statically indeterminate.

\section{Statically Indeterminate Structure}

A structure is termed as statically indeterminate, if it cannot be analyzed from principles of statics alone, i.e. A statically indeterminate structure may be classified as:

1. Externally indeterminate.

2. Internally indeterminate.

3. Both externally and internally indeterminate, (example: trussed beams, continuous trusses).

A beam, subjected only to transverse loads, with more than two reaction components, is statically indeterminate because the equations of equilibrium are not sufficient to determine all the reactions. 


\section{Externally Indeterminate Structures}

A structure is usually externally indeterminate or redundant if the reactions at the supports cannot be determined by using three equations of equilibrium, i.e. In the case of beams subjected to vertical loads only, two reactions can be determined by conditions of equilibrium.

\section{Internally Indeterminate Structures}

A truss is statically determinate internally if the total number of members

$$
\begin{aligned}
& \mathbf{m}=\mathbf{2} \mathbf{j}-\mathbf{3} \\
& \text { where } \mathbf{j}=\text { number of joints. }
\end{aligned}
$$

A truss having more than $(\mathbf{2} \mathbf{j}-\mathbf{3})$ members is statically indeterminate or redundant, the degree of indeterminacy or redundancy being equal to the number of extra members.

\section{Redundancy and Degree of Indeterminacy}

Indeterminate structures effectively have more unknowns than can be solved using the three equilibrium equations (or six equilibrium equations in 3D). The extra unknowns are called redundants.

The degree of indeterminacy is equal to the number of redundants. An indeterminate structure with 2 redundants may be said to be statically indeterminate to the second degree.

\section{Difference Between Determinate and Indeterminate Structures}

1. Determinate Structures Equilibrium conditions are fully adequate to analyze the structure; while Indeterminate Structures Conditions of equilibrium are not adequate to fully analyze the structure. 
2. Determinate Structures Bending moment or shear force at any section is independent of the material property of the structure; while Indeterminate Structures Bending moment or shear force at any section depends upon the material property.

3. Determinate Structures The bending moment or shear force at any section is independent of the cross-section or moment of inertia; while Indeterminate Structures The bending moment or shear force at any section depends upon the cross-section or moment of inertia.

4. Determinate Structures Temperature variations do not cause stresses; while Indeterminate Structures Temperature variations cause stresses.

5. Determinate Structures No stresses are caused due to lack of fit; while Indeterminate Structures Stresses are caused due to lack of fit.

6. Determinate Structures Extra conditions like compatibility of displacements are not required to analyze the structure; while Indeterminate Structures Extra conditions like compatibility of displacements are required to analyze the structure along with the equilibrium equations.

\section{Method of Analyzing Indeterminate Structures}

1. Member Flexibility.

2. Direct Stiffness Method.

- Member Stiffness Relations.

- System Stiffness Relation.

3. Moment Distribution Method.

4. Principle of Superposition; 
- Compatibility Equation and Solution.

- Force-displacement Relations.

5. Slope Deflection Method.

6. Force Method.

7. Integration Method. 


\section{Problems and Their Solutions Involving Indeterminate Structures}

EXAMPLE 1:

Find the stress at point $\mathrm{B}$ and $\mathrm{C}$ in the diagram below; given that Young Modulus, $\mathrm{E}=70 \mathrm{GPa}$ and the area of wire, $\mathrm{A}=7.069 \mathrm{~mm}^{2}$.

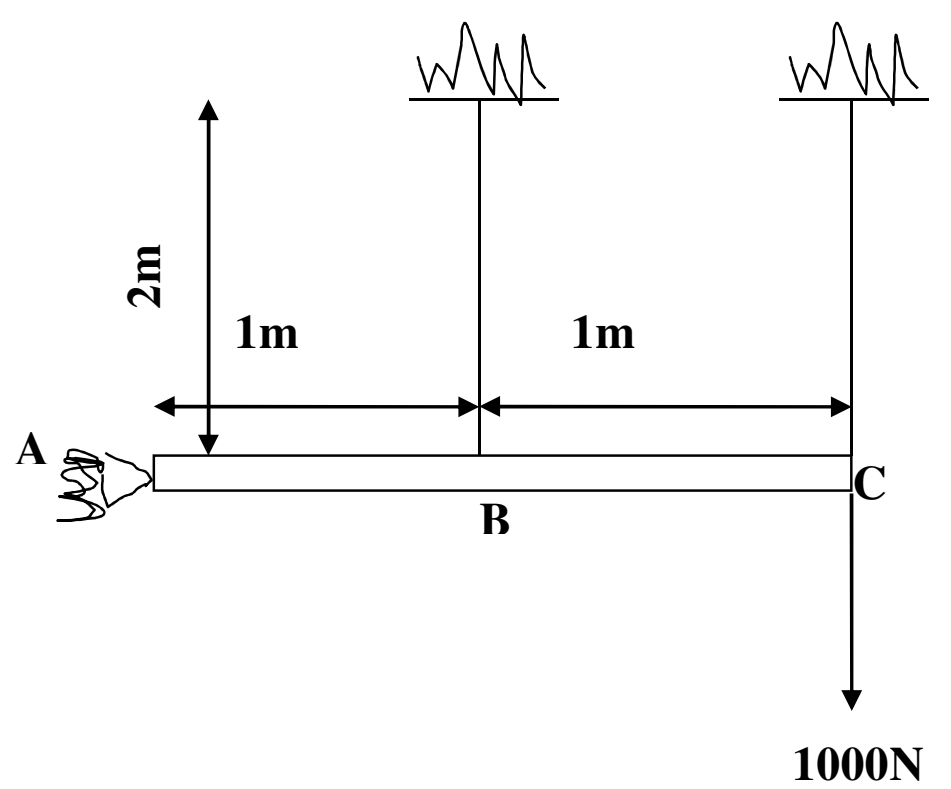

\section{Solution;}

Free Body Diagram

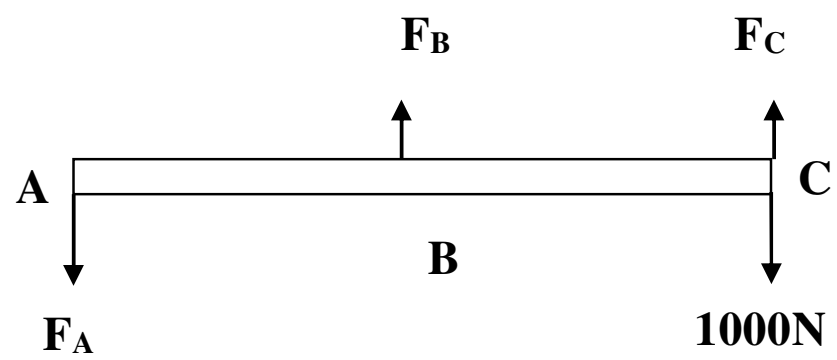


Therefore, since it is an indeterminate structure we can use the equilibrium equations as well as employ compatibility equations;

$\sum \mathbf{F}_{\mathrm{y}}=\mathbf{0}: \mathrm{F}_{\mathrm{B}}+\mathrm{F}_{\mathrm{C}}-1000 \mathrm{~N}=0$

$\sum \mathbf{F}_{\mathbf{x}}=\mathbf{0}:$ No Force

$\sum \mathbf{M}_{\mathrm{A}}=\mathbf{0}: 1 \mathrm{~m} \times \mathrm{F}_{\mathrm{B}}+2 \mathrm{~m} \times \mathrm{F}_{\mathrm{C}}-2 \mathrm{~m} \times 1000 \mathrm{~N}=0$

$1 \mathrm{~m} \times \mathrm{F}_{\mathrm{B}}+2 \mathrm{~m} \times \mathrm{F}_{\mathrm{C}}=2000 \mathrm{~N} . \mathrm{m}$ 1.

\section{Deformation Characteristics}

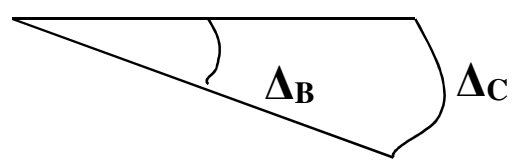

$\Delta_{\mathrm{C}}=\mathbf{2} \Delta_{\mathrm{B}}$

change in length is given by $=\frac{P L}{A E}$

$\Delta_{\mathrm{C}}=\frac{F C L C}{A C E C}$ and $\Delta_{\mathrm{B}}=\frac{F B L B}{A B E B}$

Thus, $\frac{F C L C}{A C E C}=\frac{2 F B L B}{A B E B}$

since both wires have the same Length, Area and Modulus, we cancel out A, E and L, we are now left with;

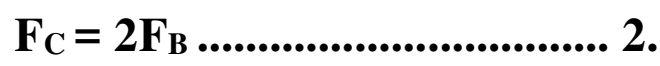

Substitute equation 2 into 1 , we have;

$1 \mathrm{~m} \times \mathrm{F}_{\mathrm{B}}+2 \mathrm{~m} \times\left(2 \mathrm{~F}_{\mathrm{B}}\right)=2000 \mathrm{~N} \cdot \mathrm{m}$

$5 \mathrm{~F}_{\mathrm{B}}=2000 \mathrm{~N}$

$\mathrm{F}_{\mathrm{B}}=400 \mathrm{~N}$ 
and since $\mathrm{F}_{\mathrm{C}}=2 \mathrm{~F}_{\mathrm{B}}$

then, $F_{C}=2(400) \mathrm{N}$

$$
\mathrm{F}_{\mathrm{C}}=800 \mathrm{~N}
$$

Now we can find the stress;

$\delta_{\mathrm{B}}=\frac{F B}{A}=\frac{400}{7.069}=56.59 \mathrm{~N} / \mathrm{mm}^{2}$.

similarly, $\boldsymbol{\delta}_{\mathbf{C}}=\mathbf{2}_{\mathbf{B}}=113.2 \mathrm{~N} / \mathrm{mm}^{2}$. 


\section{EXAMPLE 2:}

Find the reactions at point $\mathrm{A}$ and $\mathrm{C}$.

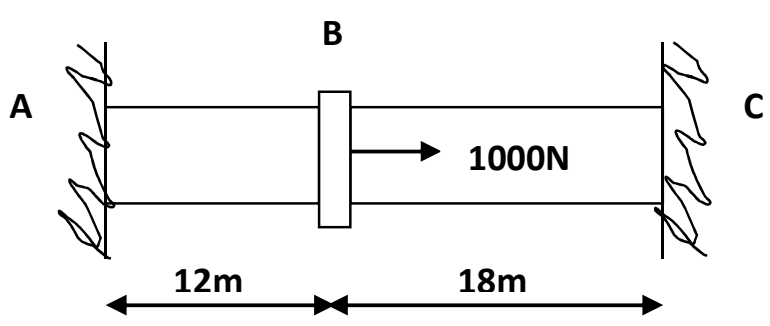

\section{Solution ;}

Free body diagram;

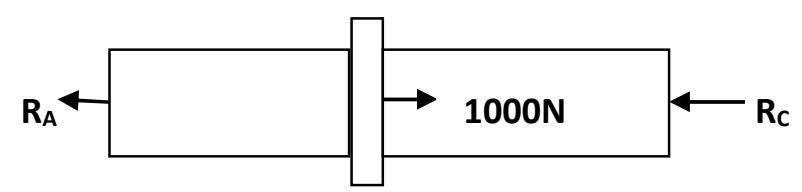

$\sum \mathbf{F}_{\mathbf{y}}=\mathbf{0}:$ No Force

$\sum \mathbf{F}_{\mathbf{x}}=\mathbf{0}:-\mathrm{R}_{\mathrm{A}}-\mathrm{R}_{\mathrm{C}}+1000 \mathrm{~N}=0$

$$
\mathrm{R}_{\mathrm{A}}+\mathrm{R}_{\mathrm{C}}=1000 \mathrm{~N}
$$

$\sum \mathbf{M}_{\mathbf{A}}=\mathbf{0}:$ No Moment

Compatibility Equations;

The overall change in length is zero.

$\delta_{\mathrm{AC}}=\delta_{\mathrm{AB}}+\delta_{\mathrm{AC}}$

We all know that change in length is given by;

$$
\frac{P a b L a b}{A a b E a b}+\frac{P b c L b c}{A b c E b c}=0
$$


Since the material is having a constant cross section all through, then A and E are the same, so we cancel them out:

$$
\text { PabLab }+ \text { PbcLbc }=0 \text {................... } 1 .
$$

Now, if we can cut a section between A and B.

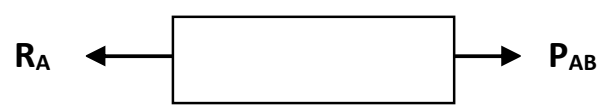

Thus, $\mathbf{P}_{\mathbf{A B}}=\mathbf{R}_{\mathbf{A}}$

And if we cut another section between B and C.

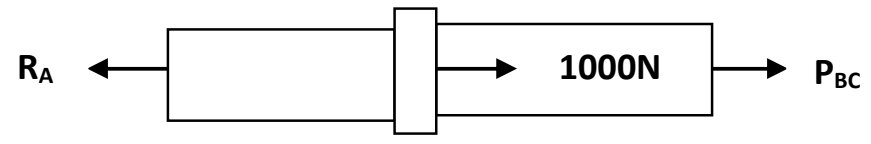

considering the statics that was found earlier above,

$\mathrm{R}_{\mathrm{A}}+\mathrm{R}_{\mathrm{C}}=1000 \mathrm{~N}$

$R_{C}=P_{B C}=R_{A}-1000 N$

Therefore, substitute the value of $\mathrm{P}_{\mathrm{BC}}$ into equation 1 ;

$$
\begin{aligned}
& \mathrm{R}_{\mathrm{A}}(12)+\left(\mathrm{R}_{\mathrm{A}}-1000\right)(18)=0 \\
& \mathrm{R}_{\mathrm{A}}(12+18)=18000 \\
& \mathrm{R}_{\mathrm{A}}=600 \mathrm{~N}
\end{aligned}
$$

$$
\begin{aligned}
& \mathrm{R}_{\mathrm{A}}+\mathrm{R}_{\mathrm{C}}=1000 \mathrm{~N} \\
& 600+\mathrm{R}_{\mathrm{C}}=1000 \mathrm{~N} \\
& \mathrm{R}_{\mathrm{C}}=400 \mathrm{~N}
\end{aligned}
$$

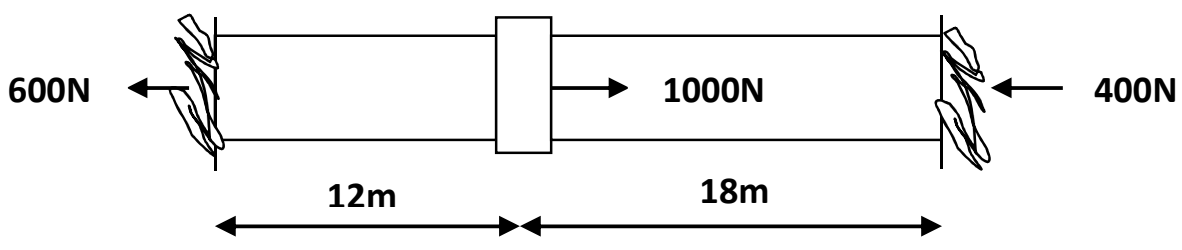




\section{EXAMPLE 3:}

Use compatibility of displacement to find the reactions at A and B in the diagram below;

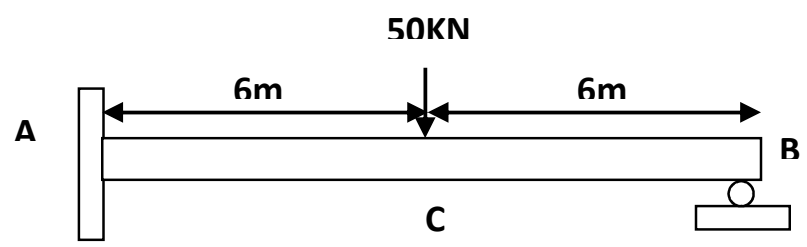

\section{Solution;}

Principle of Superposition

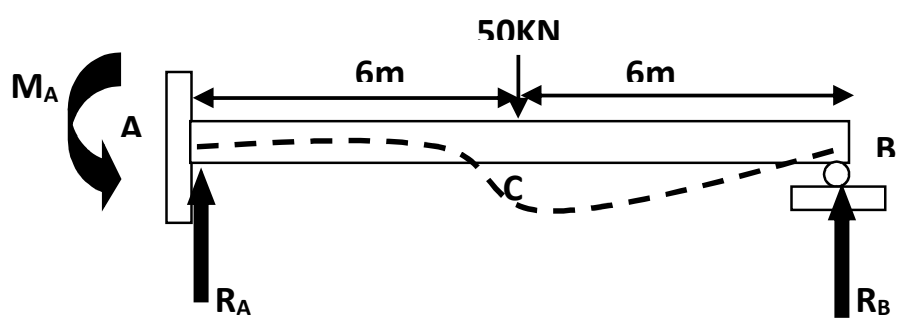

II
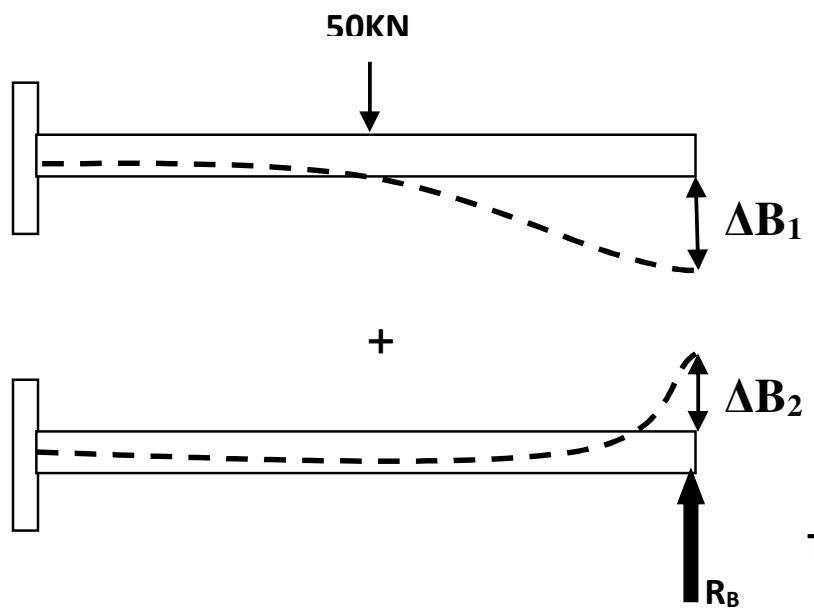

Therefore, $\Delta \mathbf{B}_{2} \times \mathbf{R}_{\mathbf{B}}$.

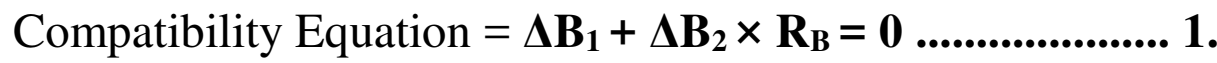




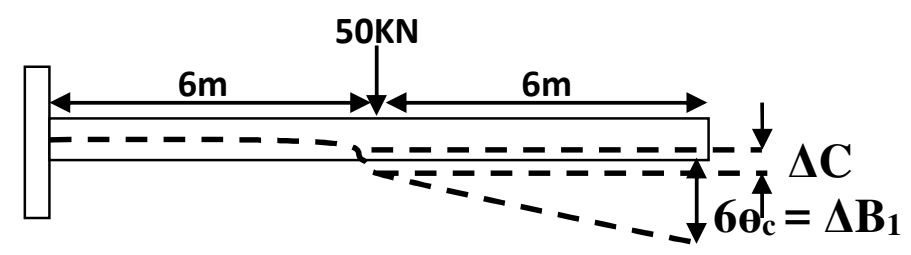

$\Delta \mathrm{B}_{1}=\Delta \mathrm{C}+(6 \mathrm{~m}) \theta_{\mathrm{c}}$ where $\theta_{\mathrm{c}}=\frac{P L^{2}}{2 E I}$
$\Delta \mathrm{B}_{1}=\frac{P L^{3}}{3 E I}+(6) \frac{P L^{2}}{2 E I}=\frac{50(6)^{3}}{3 E I}+(6) \frac{50(6)^{2}}{2 E I}=\frac{9000}{E I}-$

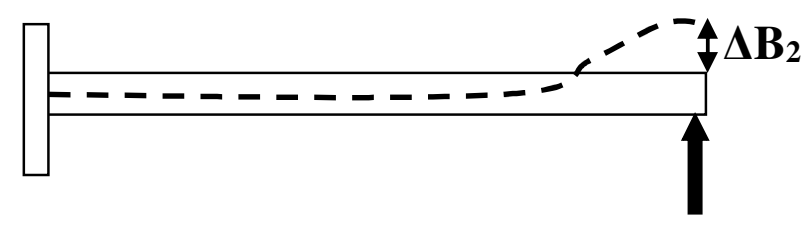

$\Delta B_{2}=\frac{P L^{3}}{3 E I}=\frac{1(12)^{3}}{3 E I}=\frac{576}{E I}+\uparrow$

Substitute $\Delta \mathbf{B}_{1}$ and $\Delta \mathbf{B}_{2}$ into Equation 1

$$
\begin{gathered}
\Delta B_{1}+\Delta B_{2} \times R_{B}=0 \\
-\frac{9000}{E I}+\frac{576}{E I} \times R B=0 \\
-9000+576 \times R B=0 \\
576 R B=9000 \\
R B=\frac{9000}{576}=15.63 \mathrm{KN}+\uparrow
\end{gathered}
$$




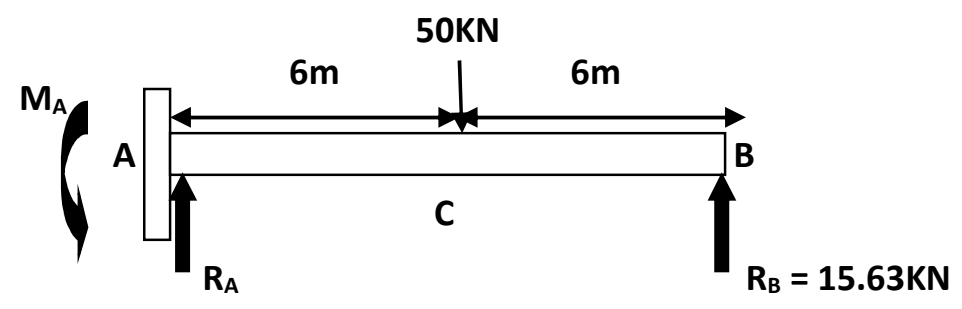

Equilibrium;

$$
\begin{aligned}
& \sum \mathbf{M}_{\mathbf{A}}=0 \rightarrow \mathrm{M}_{\mathrm{A}}-50(6)+15.63(12)=0 \\
& \mathrm{M}_{\mathrm{A}}=112.4 \mathrm{KN}+ \\
& \sum \mathbf{F}_{\mathbf{y}}=0 \rightarrow \mathrm{R}_{\mathrm{A}}-50+15.63=0 \\
& \mathrm{R}_{\mathrm{A}}=34.37 \mathrm{KN}+\uparrow
\end{aligned}
$$




\section{References}

[1] Matheson, James Adam Louis (1971). Hyperstatic structures: an introduction to the theory of statically indeterminate structures. Butterworths.

[2] Carpinteri, Alberto (1997). Structural Mechanics: A Unified Approach. Taylor \& Francis. ISBN 0-419-19160-7.

[3] "Matrix Force method" (PDF). IUST. Retrieved 29 December 2012.

[4] Cross, Hardy (1930). "Analysis of Continuous Frames by Distributing Fixed-End Moments". Proceedings of the American Society of Civil Engineers. ASCE. pp. 919-928.

[5] Błaszkowiak, Stanisław; Zbigniew Kaczkowski (1966). Iterative Methods in Structural Analysis. Pergamon Press, Państwowe Wydawnictwo Naukowe.

[6] Norris, Charles Head; John Benson Wilbur; Senol Utku (1976). Elementary Structural Analysis (3rd ed.). McGraw-Hill. pp. 327-345. ISBN 0-07-047256-4.

[7] McCormac, Jack C.; Nelson, James K. Jr. (1997). Structural Analysis: A Classical and Matrix Approach (2nd ed.). Addison-Wesley. pp. 488-538. ISBN 0-673-99753-7.

[8] Yang, Chang-hyeon (2001). Structural Analysis (in Korean) (4th ed.). Seoul: Cheong Moon Gak Publishers. pp. 391-422. ISBN 89-7088-709-1. 